DOI 10.37882/2223-2982.2021.09.40

\title{
АНГЛИЙСКОЕ СПОРТИВНОЕ ТЕРМИНООБРАЗОВАНИЕ:
}

АББРЕВИАЦИЯ

\section{ENGLISH SPORTS TERMS: ABBREVIATION}

L.Yarmolinets

O.Anisimova M.Dushko

Summary: The article discusses widespread use of complex multicomponent identifying terms in the field of sports discourse, the need to transform them by abbreviation in order to implementation of the principles of saving linguistic means and replenishment of the terminological system of sports. The analysis of English-language abbreviations in different sports based on the materials of Internet sites is presented, which allows classifying the English-language terms of sports discourse as follows: initial or letter abbreviations; truncated words; mergers; hybrid abbreviations.

Keywords: terms, term formation, abbreviations, theory of abbreviation, structural classification of abbreviated units, sports discourse, sport denotations and concepts, acronyms, acronyms, truncations, splices, hybrid abbreviations.
Ярмолинец Лариса Григорьевна

К.филол.н., профессор, Кубанский государственный университет физической культуры, спорта и туризма,

2. Краснодар

Анисимова Ольга Борисовна

К.филол.н., дочент, Кубанский государственный университет физической культуры, спорта и туризма,

2. Краснодар

anisimova_1973@mail.ru

Душко Марина Сергеевна

К.nсх.н., доцент, Кубанский государственный университет физической культуры, спорта и туризма,

2. Краснодар

Аннотация: В статье обсуждается широкое распространение сложных многокомпонентных идентифицирующих терминов в области спортивного дискурса, необходимость их преобразования путем аббревиации с целью реализации принципов экономии языковых средств и пополнения терминологической системы спорта. Представлен анализ англоязычных аббревиатур в разных видах спорта по материалам интернет-сайтов, позволяющий классифицировать англоязычные термины спортивного дискурса следующим образом: инициальные или буквенные сокращения; усеченные слова; слияния; гибридные сокращения.

Ключевые слова: термины, терминообразование, аббревиатуры, теория аббревиации, структурная классификация сокращенных единиц, спортивный дискурс, денотаты и концепты спорта, инициальные сокращения, акронимы, усечения, сращения, гибридные сокращения.

ставляют собой сложные слова или достаточно объёмные словосочетания, вербализирующие денотаты или концепты спорта с наибольшей точностью. Широкое распространение сложных многокомпонентных идентифицирующих терминов вызывает желание сохранить объем текста и информации путем введения разного рода аббревиатур, что ведет к появлению особого рода языковых единиц. Поэтому возникает необходимость в преобразовании тех или иных понятий с целью экономии в языке. Одним из таких способов преобразований является аббревиация. Вышесказанное определило цель исследования: проанализировать использование аббревиации как способа терминообразования в спортивном дискурсе.

Объект исследования: аббревиатуры в спортивной терминологии.

Практическая значимость: возможность использовать результаты исследований в отраслевой лексикографии и лингводидактике, в лекционных курсах и практических занятиях по лексикологии и стилистике. 


\section{Материалы и методы}

В исследовании использовались теоретические и эмпирические методы: обобщение научной литературы, изучение, классификация, приемы компонентного и лингвостилистического анализа, систематизация, наблюдение. Материалом исследования послужили списки спортивных аббревиатур, представленных на англоязычных сайтах.

\section{Результаты и их обсужАение}

В лингвистике отсутствует универсальная теория аббревиации, структурная классификация сокращенных единиц и т.д. Как способу словообразования, аббревиации посвящены многочисленные работы отечественных и зарубежных лингвистов. Но так и не было выработано единого мнения относительно дефиниции этого лингвистического явления. Одни ученые относят аббревиацию к самостоятельному способу словообразованию, другие же соотносят данное понятие с термином «сокращение», «acronyms». Так, Розенталь Д.Э., под аббревиацией понимает процесс сокращения слов или словосочетаний [5, с. 10]. Земская Е.А. полагает, что аббревиация делает возможным создание сокращений путем сложения усеченных основ или усеченных и полных слов [4, с. 185]. Шанский Н.М. видит процесс аббревиации как результат сокращения конца слов или в следствии опущения начала или середины слов [8, с. 287]. По мнению Суперанской А.В. аббревиация включает в себя всевозможные типы сложносокращенных и сокращенных образований [7, с. 14]. Алексеева Д.И. видит в способе аббревиации создание наименований для тех реалий и понятий, которые уже существовали раннее, но обозначались описательным способом, с помощью атрибутивных словосочетаний [1, с. 204].

Л.И. Сапогова подразделяет сокращения на: синтаксические (Liberals от Liberal party); фономорфологические (mike от microphone, doc от doctor); фонографические (sec от second, Dr от doctor); смешанные (scific от scientific fiction) [6].

Э.М. Дубенец представляет наиболее четкую систематизацию. Аббревиатуры классифицируются в зависимости от их употребления в письменной или устной речи. Так для устной речи характерны лексические сокращения, включающие инициальные, слоговые, частично сокращенные аббревиатуры. По мнения автора инициальные аббревиатуры представляют собой сокращения, состоящие из начальных букв слова, например: US (United States) - Соединенные Штаты; APA (American Psychological Association) - Американская Ассоциация Психологов.

Слоговые сокращения представляют собой сокраще- ния, образованные из начальных слогов слов, например: Internet (International Network) - всемирная компьютерная сеть связи; Wi-Fi (Wireless Fidelity) - беспроводной доступ в Интернет.

Частично сокращенные аббревиатуры образуются путем сокращения слога первого слова и добавлением второго слова полностью, например: delline (delete line) - линия удаления; e-mail (electronic mail) - электронная почта.

Графические сокращения используются с целью экономии места на письме, в то время как в устной речи применяется полная соответствующая форма. Такого рода сокращения типичны для английского языка: asap (as soon as possible) - как можно быстреe; abt (about) - o, по поводу. Для русского языка такой тип аббревиации не характерен. По мнению исследователя существует такие семантические группы, в которые входят и сокращенные графические формы и эквивалентные им полные формы, например: названия дней недели, месяцев (Fr - Friday, Oct - October); научные степени (DM - Doctor of Medicine); единицы измерения длины, веса (km. kilometers, kg. - kilogram) [3].

Зарубежные исследователи представляют несколько иную классификацию. The Oxford Companion to the English language: initialism - инициальные аббревиатуры (BBC); acronyms - акронимы (NATO); clippings - усечения (phone); blends - сращения (brunch); hybrids - гибриды базовых терминов (полуинициальные аббревиатуры полуакронимы) (VTOLL Vertical Take) [13].

D. Crystal подразделяет сокращения на: initialism инициальные аббревиатуры (BBC, DJ, MP, EEC); acronyms акронимы (UNESCO, NATO, laser); clippings - усечения (fries, fridge, flu, exam); blends - сращения (brunch, smog, Eurovision); awkward cases - смешанные (UFO or you for, ex. JP, Mr.); facetious forms - шутливые термины (TGIF Thanks God it's Friday, KCMG - Kindly Call Me God) [11].

Таким образом, процесс аббревиации способствует экономичному использованию элементов языка (звуковой и графической составляющей) для осуществления коммуникативной задачи.

Язык спортивного дискурса является обширным материалом для исследований, поскольку он обозначает те явления, которые существуют в разных культурах и странах и интересен не только узкому кругу лиц, но и огромной аудитории. Всемирная популярность спорта неизбежно ведет к появлению новых обозначений того или иного спортивного явления, слов - терминов, изучение которых на сегодняшний день вызывает огромный интерес лингвистов. В современном английском спортивном терминообразовании прослеживается тенденция к кра- 
ткости наименования для быстрого обмена информации и общения, особенно в отдельных видах спорта. Любой вид спорта имеет присущие только ему денотаты и концепты, реализуемые при помощи аббревиатур. Каждый вид спорта характеризуется своими индивидуальными правилами, особенностями тренировочного процесса, спортивным оборудованием, спортивными ассоциациями, классификаций спортивных состязаний и пр. Во многих видах спорта используются различные статистические данные и цифры, идентифицирующие техникотактические схемы и расстановки игроков в командных видах спорта. Для того, чтобы эффективно сообщать эту информацию в спортивном дискурсе используют различные сокращения.

Анализ материала исследования показал, что аббревиатуры спортивной терминологии подразделяются следующим образом: инициальные или буквенные сокращения; усеченные слова; слияния; гибридные сокращения.

Инициальные или буквенные сокращения (создаются из начальных букв слов или группы слов) и произносятся по буквам:

IOC - International Olympic Committee, SLAM - Sport as a Laboratory Assessment Model, DNF - Did not Finish, HM half Marathon, ESP - English School Cup, LJ - long jump, SP - shot put (track and fields), WR - World Records, OBO - One Behind the Other (soccer), The ABCDs of Defense - Attitude, Body, Angle, Contain, Delay (soccer), etc. $[9,10]$.

Если вновь созданная аббревиатура обозначает термин, то данное сокращение произносится в соответствии с произносительной нормой языка. Например:

ESOC European Ski Orienteering Championships/ Чемпионат Европы (лыжные дисциплины); WOC World Orienteering Championships/Чемпионат мира (кроссовые дисциплины) [12].

Усеченные сокращения представляют собой аббревиатуры, образованные путем усечения частей слова:

- начальной части слова, например: t'ment tournament, keeper - goalkeeper, b - ball, baseball;

- последней части слова, например: sec - second, fig - figure, vet - veteran, dif - difference, pts points, dh -downhill, $\mathrm{h}$ - hand timed, I - indoor, DQ disqualified;

- средней часть слова, например: ft - foot, mart market, even - e'en [i:n], ever - e'er, never- ne'er [14, 15].

Слияния - формирование нового термина путем слияния частей двух или многокомпонентных терминов: OPPR - opponent ranking, DINT - Defensive Interception, GS - Games started, FOOT-O - Foot Orienteering, SKI-O - Ski Orienteering $[9,14]$.
Примером гибридных сокращений могут быть:

а) буквенно-цифровые аббревиации:

E1 - error made by the pitcher, E2 - error made by the catcher, E3 - error made by the third baseman, E7 - error made by the left fielder, E8 - error made by the central fielder, 2pt - 2-point conversion (football), 1b - first baseman or single (baseball), 2BGY - Double boguy or worse (golf) [16 19,];

b) графические сокращения:

+/- - Fractional point awarded (taken away in hockey for being on the ice when a goal is scored), ! - seeing an exclamation point next to a player's name means that he is not in the starting lineup today [12];

c) цифровые сокращения, идентифицирующие технико-тактические схемы игры: 1-2-3 - inning (baseball), 1-2-3 - double play (baseball), 2-2-2 - 2 balls, 2 strikes, 2 outs (baseball), 5.5 - hole (baseball), one - the ball should be thrown to base (baseball) [17].

Одни и те же аббревиатуры, используемые в разных видах спорта и в соревновательной деятельности, представляют собой терминологические омонимы. Например:

T - Timing (Ice skating, Figure skating);

T - Tackle (Football, American football);

T - Teams (Olympic, Olympic Games);

$\mathrm{T}$ - Toe loop (Ice skating, Sports).

FT - full time (полное время игры);

FT - free transfer (свободный переход);

FT - first time (первый тайм).

C - catcher (baseball);

C - central (basketball and hockey) $[16,17]$.

В терминах-сленгизмах встречаются те же способы аббревиации, что и в общей терминологии спорта [https://slangit.com/terms/sports]. Большое количество сленговых аббревиаций представлены инициальными, усеченными сокращениями и слияниями. Например:

SB - Stolen base (baseball), FOMOF - Fear of Missing out on the Ball, OPPR - opponent ranking, LBW - leg before wicket ( a man of dismissing a batsman), JAG - jusla guy, ref - referee, Roy - Rookie of the year, $A B$ - at bat, SO Strikeouts, LOOGY - Left-handed One out Guy, SFTY - safety, fit - fitness, abs - abdomen, reps - repetitions, base brawl baseball brawl [18].

Исходя из выше сказанного, аббревиацию можно определить как замену слова или словосочетания более энергоемкой языковой единицей без изменения основного смысла исходного понятия.

\section{Зак^ючение}

Таким образом, процесс аббревиации как один из способов словообразования широко представлен в англоязычном спортивном дискурсе, на что указывает 
большое количество интернет-сайтов, представляющих англоязычные аббревиатуры в разных видах спорта. Сокращенные слова и словосочетания, спортивные аббревиатуры реализуют принципы экономии языковых средств и пополняют терминологическую систему спорта. Анализ материала исследования выявил, что в англоязычной терминологии спортивного дискурса от- мечаются большое количество слияний. Это можно объяснить тем, что в терминологии дискурсов различных видов спорта преобладают многокомпонентные идентифицирующие термины. Соревновательная деятельность подразумевает технико-тактические схемы, а также статистику, поэтому в терминологии представлены цифровые и буквенно-цифровые сокращения.

\section{ЛИТЕРАТУРА}

1. Алексеев А.В., Каширина Н.А. Перевод аббревиатур и акронимов в официальных текстах олимпийской тематики // Современные наукоёмкие технологии. - 2013. - №7-1. -75 С.

2. Блеер А.Н., Суслов Ф.П., Тышлер Д.А. Терминология спорта. Толковый словарь-справочник. - М.: Академия, 2010. - 464 с.

3. Дубенец Э.М. Лексикология современного английского языка. - М.: «Глосса-Пресс», 2012. - 192 с.

4. Земская Е.А. Современный русский язык. Словообразование. Учебное пособие. - Москва, 2012. - 328 с.

5. Розенталь Д.Э., Теленкова М.А. Справочник по русскому языку. Словарь лингвистических терминов. - Москва: 000 «Издательский дом «ОНИКС 21 век»: 000 «Издательство «Мир и Образование», 2003. - 399 с.

6. Сапогова Л.И. Опыт семантико-стилистического сопоставления морфемных усечений с прототипами: дисс. ... канд. филол. наук: 10.00.00 / Л.И. Сапогова. - Тула, 1968. - 275 с.

7. Суперанская А.В., Подольская Н.В., Васильева Н.В. Общая терминология: вопросы теории / Отв. ред. Т.Л. Канделаки. - 6-е изд. - Москва: URSS: ЛиброKOM, 2012. - 243. - ISBN 978-5-397-02414-3.

8. Шанский Н.М. Очерки по русскому словообразованию. Серия Лингвистическое наследие XX века. - 4-е изд., доп. - Москва: URSS: KoмKнига, 2016. - 338 с. ISBN 978-5-9710-2399-9.

9. Acronyms for «SPORT» [Электронный ресурс]. - URL: https://acronym-maker.com/acronym/sport. (дата обращения: 06.04.2021).

10. Acronyms \& Abbreviations [Электронный ресурc]. - URL: https://www.abbreviations.com/. (дата обращения: 06.04.2021).

11. Crystal D. English as a global language. - Publisher: Cambridge University Press, 2003. - 228 p. - ISBN 9780521530323. - URL: https: //doi.org/10.1017/ CB09780511486999.

12. Important Sports Abbreviations [Электронный ресурс]. - URL: https://affairscloud.com/important-sports-abbreviations-pdf/. (дата 0бращения: 06.04.2021).

13. McArthur T., Lam-McArthur J., Fontaine L. Oxford Companion to the English Language (Oxford Quick Reference). - 2nd Edition. - Publisher: Oxford University

Press, 2018. - 736 p. - ISBN: 0199661286. - URL: https://drive.google.com/file/d/197g3CfWeRq3N28J9v1_EeKEIXsv0DNOv/view.

14. Sports Abbreviations [Электронный ресурc]. - URL: https://www.allacronyms.com/sports/abbreviations (дата обращения: 16.04.2021).

15. Sports Abbreviations. Acronyms [Электронный ресурc]. - URL: https://www.abbreviations.com/acronyms/SPORTS (дата 0бращения: 16.04.2021).

16. Sports Abbreviations. Category [Электронный ресурc]. - URL: https://www.abbreviations.com/category/SPORTS. (дата обращения: 16.04.2021).

17. Sports Acronyms [Электронный ресурc]. - URL: https://acronym-guide.com/sports-acronyms. (дата обращения: 16.04.2021).

18. Sports Slang [Электронный ресурc]. - URL: https://www.bu.edu/mfeldman/Slang/sports/. (дата обращения: 16.04.2021).

19. Sports Slang terms [Электронный ресурс]. - URL: https://slangit.com/terms/sports. (дата обращения: 16.04.2021).

(с) Ярмолинец Лариса Григорьевна, Анисимова Ольга Борисовна (anisimova_1973@mail.ru),

$$
\text { Душко Марина Сергеевна. }
$$

Журнал «Современная наука: актуальные проблемы теории и практики» 